\title{
Smart City as a Model for Sustainable Development of Territories
}

\author{
Konstantin Semyachkov* \\ Institute of Economics, The Ural Branch of Russian Academy of Sciences, Yekaterinburg, \\ Moskovskaya 29, Russia
}

\begin{abstract}
The article examines the impact of digital technologies on the sustainable development of ecological and economic systems. The main aspects that make the development of digital technologies especially relevant for environmental modernization and sustainable development are analyzed. It is shown that the large-scale use of digital technologies contributes to the development of new tools, models and methods of urban management. One of the promising areas for the development of the urban environment in these conditions is the concept of a smart city. Based on the analysis of research on the topic of smart cities, the effects of the use of the smart city model for the formation of the foundations of sustainable development of territories are noted.
\end{abstract}

\section{Introduction}

The search for conditions for long-term sustainable development with increasing environmental challenges and threats is the most important goal of mankind at the present time. The growth of the world economy, an increase in the population, urbanization of territories, the active use of natural resources and, as a result, an increase in the environmental load on the environment is increasingly becoming a cause for concern in the ranks of the expert community, among individual states and society as a whole. The importance of finding new solutions in the environmental field to reduce the burden on the environment is increasingly noted. At the same time, the need to improve the efficiency of the use of natural resources, the transition to renewable energy sources, the development of environmentally friendly production methods and other factors of sustainable development are noted $[1,2]$.

Sustainable socio-economic development is a natural desire of citizens, who are increasingly faced with environmental problems. Digital technologies are one of the drivers of sustainable development in a post-industrial society. Increasingly, advanced countries note the importance of using digital technologies in solving global problems in order to reduce the negative impact on the environment, increase the efficiency of the use of natural resources, and educate in the environmental sphere. Digital technologies are a prerequisite for the transformation of socio-economic relations, the emergence of new business models, which is also a factor in increasing the sustainability of development. One of the most

\footnotetext{
*Corresponding author: k.semyachkov@mail.ru
} 
promising models for sustainable development of territories based on digital technologies is the smart city model [3].

Digital technology is a powerful transformative factor in traditional urban infrastructure. Through the introduction of digital technologies, the physical objects of infrastructure and the principles of urban environment management are being transformed. A lot of intelligent technologies are used in various urban systems with the aim of rational use of resources, reducing the level of environmental pollution, improving the quality of management, which ultimately leads to an increase in the quality of life of citizens. In this regard, research practice in the field of digital technologies and their impact on socio-economic systems is of particular importance in the modern conditions of the formation of a digital society. In modern cities, there are a number of avenues for smart solutions that align with sustainable development goals. In this way, digital technologies can be used to advance sustainable development principles and, therefore, to address the challenges of urbanization. Despite a sufficient number of studies in the field of urban development in the context of digitalization, most of them are of a highly specialized nature. At the same time, there are still no generally accepted theoretical approaches to the development of smart cities in the social sciences. Many modern cities have focused on development based on the smart city model [4].

Cities such as Seoul, Barcelona, Tokyo, New York, Moscow are leaders in the implementation of digital technologies in various aspects of the urban environment. In various industry initiatives, government programs, the need to develop environmentally friendly digital technologies within the framework of the functioning of modern cities is increasingly emphasized [5].

As the smart city model takes on an important role in the development of modern cities and provides significant impact on the development of territories, it is important to study its role in achieving balanced ecological and economic development of modern society [6]. Hence, the purpose of this study is to systematize the main trends in the influence of the smart city model on increasing the sustainability of the development of territories.

\section{Methods}

Digital technologies in a broad sense are one of the most important driving forces for the innovative development of the modern economy. Such areas of the economy as the creation of communication and computer equipment, software are currently ahead of other areas of activity and have a high rating among the indicators of the effectiveness of innovations by sector, which indicates the relevance of the development of these areas for economic growth and structural changes in the economy. It should also be noted that digital technologies themselves are a factor in the creation and diffusion of innovations. They contribute to the building of communication systems, the accumulation and exchange of data, while creating an environment for innovative activity in other industries.

Exploring the issues of balanced ecological and economic development, the following main aspects related to the economic sphere are often identified [7-10].

First, it is the production of goods and services. The higher the level of production per capita, the larger the world's population, the greater, other things being equal, the environmental burden associated with production.

Secondly, it is the energy sector of the economy. The production and consumption of energy resources is associated with the greatest burden on the environment. Accordingly, issues related to the production and consumption of energy resources have determined the intensity of emissions for decades. 
Thirdly, it is the level of personal consumption and lifestyle. Higher consumption per capita will be accompanied by the use of more material costs and energy, as well as lead to negative impact on the environment.

Fourth, this is the housing and communal services, whose influence is of particular importance, since the intensity of resource consumption in this area is high, and the modernization of the existing infrastructure is quite resource-intensive.

The smart city concept reflects the idea of an effective social and economic organization based on digital technologies [11]. Often, there are four areas of development that are key in the process of creating smart cities: the environmental aspect is associated with the need to preserve the environment; the social aspect is associated with meeting the needs of society; the economic aspect is related to the efficiency of production processes; the institutional aspect is related to the development of smart city institutions. The problems caused by rapid urbanization are among the most important problems of our time. On the other hand, they represent significant opportunities for private business development in the formation of sustainable, economically competitive cities of the future. In such conditions, it becomes important to focus on how social and technological innovation can help ensure sustainable development of territories [12, 13].

As an object of research in this article, we considered the modern concept of the development of a smart city in various manifestations of economic activity. The subject of this study is economic relations that are being formed in various areas of the economic application of digital technologies in smart cities. The analyzed data are scientific research, reflected in the periodicals, as well as the author's results in the study of the formation of smart cities.

\section{Results}

At the beginning of the 21 st century, the digital technology sector is the fastest growing sector in a significant number of countries. Four different aspects can be noted that make the development of digital technologies especially relevant for environmental modernization and sustainable development:

- software development is critical to achieving high productivity growth, since the use of software, on the one hand, means flexible use of technologies, and on the other hand, the use of software requires the standardization of production processes, which makes them more environmentally friendly. In addition, software development is a waste-free process and therefore has enormous environmental potential;

- there is a high level of technical progress in the digital technology sector, and accordingly, the environmental impact in the production of innovative products will decrease;

- the expansion of the Internet and the growing global access to data networks are reducing communication costs, information costs and operating costs. In addition, the Internet is helping to bring suppliers and consumers together through new sharing economy models (such as Uber, Airbnb) that are more environmentally efficient;

- there is an additional effect from the development of the Internet, which creates conditions for the exchange of information and the dissemination of an environmentally friendly lifestyle of people.

As for the smart city model, among its main positive aspects that affect the sustainable development of territories, the following can be noted:

- the ability to respond to the changing characteristics of urban systems, the availability of tools and methods to implement the dynamic concept of urban environment development; 
- integrating and improving urban systems, promoting cooperation and coordination in the context of developing a sustainable urban environment;

- an integrated approach to the development of the urban environment through monitoring, automation, control, management and optimization using digital technology tools;

- development of infrastructure, technology, social and human capital;

- high quality management of infrastructure facilities and resources;

- increasing social justice, environmental safety, taking into account cultural characteristics.

\section{Discussion}

The study of the influence of digital technologies on the sustainable ecological and economic development of territories shows that there are several levels of such influence.

First, there is the system level. Digital technologies are the driver of systemic transformations in the economy, the replacement of industrial systems with post-industrial ones. Such changes are accompanied by a reduction in the burden on the environment in a natural way, since resource-intensive, polluting industries are being replaced by innovative companies that have a minimal impact on the environment.

Secondly, this is the industry level. Modernization of production facilities in certain industries, the introduction of digital technologies in order to increase production efficiency, the application of advanced environmental standards are factors in reducing the negative impact on the environment and increasing the sustainability of development.

Thirdly, this is the organizational level. Such models of economic interactions as the sharing economy, as well as new approaches to organizing and managing the processes of the urban environment, based on modern digital technologies, are an effective factor in reducing the negative impact within local socio-economic systems.

\section{Conclusion}

In this study, in order to determine the impact of modern digital technologies on sustainable development, the following theoretical results are obtained.

First, it is shown that digital technologies are the basis for the development of modern society and have an impact on various spheres of public life, including relations with the natural environment.

Secondly, a number of areas are considered that make the development of digital technologies especially relevant for environmental modernization and sustainable development of territories.

Thirdly, some theoretical features of the formation of smart cities are considered, features are noted due to which the smart city model can be considered an effective tool for sustainable development of territories.

Fourthly, the levels of influence of digital technologies on sustainable ecological and economic development of territories are considered.

This study is a theoretical basis for conducting other, more specialized studies to explore the impact of modern digital technologies and the smart city model on the sustainable development of territories.

The study was financially supported by the Grants Council of the President of the Russian Federation, project MK-526.2020.6 


\section{References}

1. A. Sdiri, B. Elleuch, H. Ben Dhia, Environmental Science and Pollution Research, 23 (16), 15789-15791 (2016)

2. P.J.J. Welfens, C. Lutz, Mineral Economics, 24(2), 2-3, (2012)

3. A.V. Anttiroiko, P. Valkama, S.J. Bailey, AI \& Society, 29(3), 323-334 (2014)

4. M. Batty, K. Axhausen, F. Giannotti, A. Pozdnoukhov, A. Bazzani, M. Wachowicz, G. Ouzounis, Y. Portugali, European Physical Journal, 214, 481-518 (2012)

5. D. Belanche, L. Casaló, C. Orús, Cities, 50, 75-81 (2016)

6. D. Carter, Journal of the Knowledge Economy, 4(2), 169-189 (2013)

7. P. Neirotti, A. De Marco, A. Cagliano, G. Mangano, F. Cities, 38, 25-36 (2014)

8. M. Misra, D. Kumar, J Indian Soc Remote Sens, 48, 1639-1643 (2020)

9. H. Ahvenniemi, A. Huovila, Environ Dev Sustain, 23, 4174-4200 (2021)

10. M.V. Ramesh, R. Prabha, H. Thirugnanam, et al., CSIT, 8, 213-230 (2020)

11. M. Jadoul, Elektrotechnik und Informationstechnik, 133(7), 341-344 (2016)

12. N.Streitz, Journal of Ambient Intelligence and Humanized Computing, 10(2), 791-812 (2019)

13. E.V. Popov, K.A. Semyachkov, Economy of region, 16(1), 14-27 (2020) 